commissioned by Janssen to conduct the research reported in this abstract, Chloe Tolley Consultant of: Adelphi Values a health outcomes research company commissioned by Janssen to conduct the research reported in this abstract, Patricia Delong Employee of: Janssen, Elizabeth C Hsia Shareholder of: Johnson \& Johnson, Employee of: Janssen Research \& Development, LLC DOI: 10.1136/annrheumdis-2020-eular.5634

\section{AB1333-HPR FIBROMYALGIA SYNDROME IN MEDICAL STUDENTS}

I. Akcin ${ }^{1}$, M. Gur ${ }^{2}$, R. Piskin Sagir ${ }^{2}$, B. Oz ${ }^{2}$, A. Karatas ${ }^{2}$, S. S. Koca ${ }^{2}{ }^{1}$ Firat University, Elazig, Turkey; ${ }^{2}$ Firat University, Rheumatology, Elazig, Turkey

Background: At the university, students begin to be responsible for their own life decisions and lifestyles. First year students are required to adapt especially to a new learning environment and to cope with the academic and social demands of vocational education. High academic expectations are stressful and can pose a risk to students mental and physical health. Anxiety and depression are among the most common psychiatric problems among students.

Objectives: The aim of this study is to evaluate the prevalence of fibromyalgia syndrome (FMS) in medical students and to compare students from engineering faculty.

Methods: 392 (284 faculty of medicine, 108 faculty of engineering) students selected from Firat University Faculty of Medicine and Engineering were included in the study. Hospital Anxiety and Depression Scale (HADS) forms were filled in for all participants. Anxiety and depression among students of medical and engineering were examined. Moreover, 2016 ACR FMS classification criteria was used to select the student who have FMS.

Results: In our sample, 185 (47.1\%) and 207 (52.9\%) of participants were male and female, respectively. HADS anxiety and HADS depression scores were significantly higher in engineering students than in medical students (mean HADS anxiety and depression scores were 9.07; 10.29, $\mathrm{p}=0.007$ and $7.61 ; 8.52, \mathrm{p}=$ 0.039 , respectively). While a significant difference was found among medical and engineering students in terms of HADS anxiety and depression scores in men $(p<0.001$ and $p=0.006)$, no significant difference was found in women $(p=0.676$ and $p=0.278)$. On the other hand, $46(16.1 \%)$ of medical students and $13(11.7 \%)$ of students from engineering faculty have FMS $(p=0.170)$.

Conclusion: FMS prevalences are similar in the medical students and students from engineering faculty. However, anxiety and depression are more common among male engineering students than medical students. This may be related to future employment anxiety among students from engineering faculty.

References:

[1] Cheung T, et al. Depression, Anxiety and Symptoms of Stress among Baccalaureate Nursing Students in Hong Kong: A Cross-Sectional Study. Int J Environ Res Public Health. 2016 Aug 3;13(8).

Disclosure of Interests: None declared

DOI: 10.1136/annrheumdis-2020-eular.5842

\section{AB1334-HPR BARRIERS AND FACILITATORS TO PHYSICAL ACTIVITY IN JUVENILE IDIOPATHIC ARTHRITIS (JIA): A SCOPING REVIEW}

K. O Donoghue ${ }^{1}$, L. Larkin ${ }^{2,3} .{ }^{1}$ University of Limerick, Limerick, Ireland; ${ }^{2}$ Health Research Institute, University of Limerick, Castletroy, Ireland; ${ }^{3}$ University of Limerick, School of Allied Health, Faculty of Education \& Health Sciences, Castletroy, Ireland

Background: Physical activity is an important aspect in the management of JIA (1). However physical activity levels are low in this population (2). Limited research has been conducted to identify definitive barriers and facilitators to physical activity in children and adolescents who have JIA.

Objectives: The objective of this scoping review was to identify the common barriers and facilitators to physical activity in JIA.

Methods: Original studies, either quantitative or qualitative, including participants with a diagnosis of JIA, who were under 18 years of age were included. Two independent reviewers carried out a search of the literature and full text reviews of papers to determine eligibility for inclusion. The Critical Skills Appraisal Programme (CASP), Appraisal tool for Cross-Sectional Studies (AXIS) and Downs and Black critical appraisal tools were used to assess the quality of the included research articles.

Results: Eighteen studies were included in the review. The included studies were of a variety of low, moderate and high quality. The synthesis of the data identified pain to be the most common barrier and the modification of physical activities to the need of the individual to be the most common facilitator to physical activity in JIA.

Conclusion: Identifying the most common barriers and facilitators to physical activity allows clinicians to apply better management strategies when treating an individual with JIA. Our findings demonstrate the need for further research in this area to assist increasing physical activity participation for children and adolescents who have JIA.

\section{References:}

[1] Kuntze, G., Nesbitt, C., Whittaker, J.L., Nettel-Aguirre, A., Toomey, C., Esau S., Doyle-Baker, P.K., Shank, J., Brooks, J., Benseler, S., Emery, C.A. (2018) 'Exercise Therapy in Juvenile Idiopathic Arthritis: A Systematic Review and Meta-Analysis', Archives of Physical Medicine and Rehabilitation, 99(1), 178-193

[2] Bos, G.J.F.J., Lelieveld, O.T.H.M., Armbrust, W., Sauer, P.J.J., Geertzen, J.H.B., Dijkstra, P.U. (2016) 'Physical activity in children with Juvenile Idiopathic Arthritis compared to controls', Pediatric Rheumatology, 14(1), 42.

Disclosure of Interests: None declared

DOI: 10.1136/annrheumdis-2020-eular.3550

\section{AB1335-HPR HEALTH PROFESSIONALS' PERSPECTIVE ON THE BENEFITS AND RISKS OF LOW-DOSE GLUCOCORTICOIDS IN RHEUMATOID ARTHRITIS - AN INTERNATIONAL SURVEY OF 444 HEALTH PROFESSIONALS}

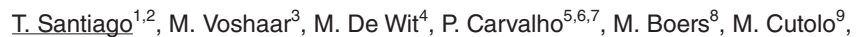
F. Buttgereit ${ }^{10}$, J. A. P. Da Silva ${ }^{1,2} \cdot{ }^{1}$ Centro Hospitalar e Universitário de Coimbra, Rheumatology, Coimbra, Portugal; ${ }^{2}$ University of Coimbra, Faculty of Medicine, Coimbra, Portugal; ${ }^{3}$ University of Twente, Department of Psychology, Health and Technology, Enschede, Netherlands and Stichting Tools Patient Empowerment, Amsterdam, Netherlands; ${ }^{4}$ Stichting Tools Patient Empowerment, Amsterdam, Netherlands; ${ }^{5}$ Centro Hospitalar Universitário do Algarve, Rheumatology, Faro, Portugal; ${ }^{6}$ Lisbon Academic Medical Centre, Lisbon, Portugal; ${ }^{7}$ Algarve Biomedical Center, Faro, Portugal; ${ }^{8}$ Department of Epidemiology and Biostatistics; and Amsterdam Rheumatology and Immunology Center, Amsterdam University Medical Centers, Vrije Universiteit, Amsterdam, Netherlands; ${ }^{9}$ Research Laboratory and Academic Division of Clinical Rheumatology, Department of Internal Medicine, University of Genova, IRCCS Polyclinic Hospital San Martino, Genova, Italy; ${ }^{10}$ Department of Rheumatology and Clinical Immunology, Charité University Medicine Berlin, Berlin, Germany

Background: The Glucocorticoid Low-dose Outcome in Rheumatoid Arthritis Study (GLORIA) is an international investigator-initiated pragmatic randomized trial designed to study the effects of low-dose glucocorticoids (GCs) in elderly patients with Rheumatoid Arthritis (RA).

The research team is also committed to promote a better understanding of the risks and benefits of these drugs among health professionals and patients. In order to achieve these goals, it is important to assess the current ideas and concerns of patients regarding GCs.

Objectives: To evaluate the current patient perspective on the efficacy and risks of GCs in RA patients who are or have been treated with GCs.

Methods: Patients with RA completed an online survey (with 5 closed questions regarding efficacy and safety) presented in their native language. RA patients were recruited through a variety of patient organizations representing three continents. Patients were invited to participate through national patient organizations. In the USA, patients were also invited to participate through MediGuard.org. Participants were asked for their level of agreement on a 5-point Likert scale.

Results: 1344 RA patients with exposure to GCs, from Brazil, USA, UK, Portu gal, Netherlands, Germany and 24 other countries** participated: $89 \%$ female, mean age (SD) 52 (14) years and mean disease duration 13 (11) years. The majority of participants (84\%) had $\geq 10$ years of education. The duration of GCs exposure was 1.6 (4.2) years. The majority of participants had read articles or pamphlets on the benefits or harms of GC therapy.

Regarding GCs efficacy (table 1), high levels of endorsement were found: about $2 / 3$ of patients considered that GCs as very useful in their case, more than half considered that GCs were effective even at low doses, and agreed that GC improved RA symptoms within days.

Regarding safety (table 1), 1/3 of the participants reported having suffered some form of serious adverse events (AEs) due to GCs, and $9 \%$ perceived this as "life-threatening. Adverse events had a serious impact on quality of life, according to about $1 / 3$ of the respondents.

Conclusion: Patients with RA exposed to GC report a strong conviction that GCs are very useful and effective for the treatment of their RA, even at low doses. This is accompanied by an important prevalence of serious AEs. Understanding the patient perspective can improve shared decision-making between patient and rheumatologist.

Funding statement: This project has received funding from the European Union's Horizon 2020 research and innovation programme under grant agreement No 634886 . 


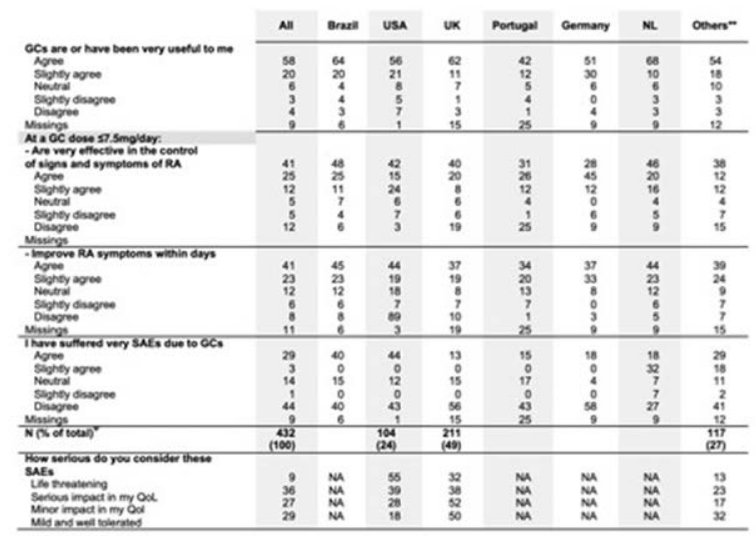

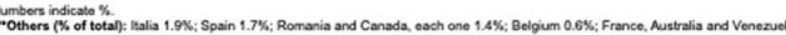

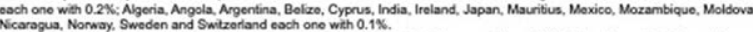
"The Portugueso. Germany and Deutschland version as woll as the Engiah survey through MedGuard.org. didn't have this question due

Disclosure of Interests: Tânia Santiago: None declared, Marieke Voshaar Grant/research support from: part of phd research, Speakers bureau: conducting a workshop (Pfizer), Maarten de Wit Grant/research support from: Dr. de Wit reports personal fees from Ely Lilly, 2019, personal fees from Celgene, 2019, personal fees from Pfizer, 2019, personal fees from Janssen-Cilag, 2017, outside the submitted work., Consultant of: Dr. de Wit reports personal fees from Ely Lilly, 2019, personal fees from Celgene, 2019, personal fees from Pfizer, 2019, personal fees from Janssen-Cilag, 2017, outside the submitted work., Speakers bureau: Dr. de Wit reports personal fees from Ely Lilly, 2019, personal fees from Celgene, 2019, personal fees from Pfizer, 2019, personal fees from Janssen-Cilag, 2017, outside the submitted work., Pedro Carvalho: None declared, Maarten Boers: None declared, Maurizio Cutolo Grant/research support from: Bristol-Myers Squibb, Actelion, Celgene, Consultant of: Bristol-Myers Squibb, Speakers bureau: Sigma-Alpha, Frank Buttgereit Grant/research support from: Amgen, BMS, Celgene, Generic Assays, GSK, Hexal, Horizon, Lilly, medac, Mundipharma, Novartis, Pfizer, Roche, and Sanofi., José Antonio P. da Silva Grant/ research support from: Pfizer, Abbvie, Consultant of: Pfizer, AbbVie, Roche, Lilly, Novartis

DOI: 10.1136/annrheumdis-2020-eular.3277

\section{AB1336-HPR NON-PHARMACOLOGIC TOPICS RELEVANT FOR CLINICAL RESEARCH IN RHEUMATIC DISEASES: THE PATIENT PERSPECTIVE}

F. Ingegnoli ${ }^{1,2}$, T. Schioppo $^{1,2}$, T. Ubiali $^{1}$, S. Ostuzzi ${ }^{3}$, M. Buoli ${ }^{2,4}$, V. Bollati $^{2,5}$, R. Caporali ${ }^{1,2},{ }^{1}$ G Pini Hospital, Clinical Rheumatology Unit, Milan, Italy; ${ }^{2}$ Università degli Studi di Milano, Milan, Italy: ${ }^{3}$ A LOMAR Lombard Association for Rheumatic Diseases, Milan, Italy; ${ }^{4}$ IRCCS Ca'Granda Policlinico, Milan, Italy; ${ }^{5}$ EPIGET Lab, Milan, Italy

Background: The research approach on Rheumatic diseases (RDs) is challenging and patient involvement as partners in medical research is an emerging force to obtain relevant information and to add unique skills, values and experiences to research. Despite growing interest in non-pharmacologic aspects of clinical research in RDs, the patients' perspective is currently poorly explored.

Objectives: To identify and rank the priorities for clinical research according to patients' perspective.

Methods: A structured face-to-face meeting between physicians and a patient representative was convened to list the non-pharmacologic topics relevant to RD patients. A cross-sectional no-profit on-line anonymous survey was devised to evaluate opinions of RD patients. They were asked to rate the following topics: food/nutrition, air pollution, smoking, work activity, social participation, physical activity, emotional well-being/stress, alternative medicine, and patient-physician relationship. Moreover, patients were asked to explain for which reason a topic was considered important (disease prevention, halting disease progression, symptoms control and disease cure). The survey was disseminated by ALOMAR (Lombard Association for Rheumatic Diseases) between June and October 2019. Results: 200 rheumatic patients completed the survey: 130 inflammatory arthritis, 50 connective tissue diseases/vasculitis, and 20 among osteoarthritis, gout, condrocalcinosis, polymyalgia and primary fibromyalgia. Respondents were 178 female with median age of 50 years and median disease duration of 7 years. Among the nine topics identified, the one most rated by patients was the doctor-patient relationship; $188(94 \%)$ of respondents considered this topic very or extremely important (see table below). In descending order, patients rated very or extremely important: psychological well-being/stress 185 (92.5\%), physical activity $155(77.5 \%)$, nutrition, eating habits and alcohol 150 (75\%), alternative therapies $144(72 \%)$, work activity $144(72 \%)$, environmental pollution $134(67 \%)$ social life $121(60.5 \%)$ and cigarette smoke $119(59.5 \%)$. The topics considered relevant was perceived to be able to influence disease symptoms. Regarding RD prevention, environmental pollution and cigarette smoking were considered the most important topics, while fewer patients believed that research on other topics could help to stop disease progression or to achieve disease healing.

\begin{tabular}{lccc}
\hline Ranking & Topic & $\begin{array}{c}\text { Not or quite } \\
\text { important }\end{array}$ & $\begin{array}{c}\text { Very or extremely } \\
\text { important }\end{array}$ \\
\hline 1 & $\begin{array}{c}\text { Doctor-patient relationship, } \mathrm{n}(\%) \\
\text { Psychological well-being/stress, } \mathrm{n}(\%)\end{array}$ & $12(6.0)$ & $188(94.0)$ \\
2 & Physical activity, $\mathrm{n}(\%)$ & $45(22.5)$ & $185(92.5)$ \\
3 & Nutrition/eating habits/alcohol, $\mathrm{n}(\%)$ & $50(25.0)$ & $155(77.5)$ \\
4 & Alternative therapies, $\mathrm{n}(\%)$ & $56(28.0)$ & $144(72.0)$ \\
5 & Work activity, $\mathrm{n}(\%)$ & $56(28.0)$ & $144(72.0)$ \\
6 & Environmental pollution, $\mathrm{n}(\%)$ & $66(33.0)$ & $134(67.0)$ \\
7 & Social life, $\mathrm{n}(\%)$ & $79(39.5)$ & $121(60.5)$ \\
8 & Cigarette smoke, $\mathrm{n}(\%)$ & $81(40.5)$ & $119(59.5)$ \\
9 & & &
\end{tabular}

Conclusion: This survey highlights the relevance of several unmet needs. The holistic approach, in terms of medical consultation and psychological well-being is considered the most important component able to influence disease perception. By capturing patient opinions on non-pharmacological topics for clinica research, this survey indicates that the active patient involvement is essential to design successful translational studies and improve clinical outcomes.

Acknowledgments: We thank the Lombard Association of Rheumatic Diseases (ALOMAR) for its contribution to plan and disseminate the survey and the group that sustain systemic sclerosis (GILS).

Disclosure of Interests: Francesca Ingegnoli: None declared, Tommaso Schioppo: None declared, Tania Ubiali: None declared, Silvia Ostuzzi: None declared, Massimiliano Buoli: None declared, Valentina Bollati: None declared, Roberto Caporali Consultant of: AbbVie; Gilead Sciences, Inc.; Lilly; Merck Sharp \& Dohme; Celgene; Bristol-Myers Squibb; Pfizer; UCB, Speakers bureau: Abbvie; Bristol-Myers Squibb; Celgene; Lilly; Gilead Sciences, Inc; MSD; Pfizer; Roche; UCB

DOI: 10.1136/annrheumdis-2020-eular.700

\section{AB1337-HPR PATIENTS' EXPERIENCE OF INVOLVEMENT IN A RHEUMATOLOGY OUTPATIENT CLINIC}

\section{P. Toftegaard ${ }^{1} .{ }^{1}$ Svendborg, Rheumatology, Svendborg, Denmark}

Background: Involvement in own treatment and care is a wish from patients and a vision from politicians in Denmark. $(1,2)$ In outpatient rheumatology patient involvement also leads to increased patient satisfaction, better quality of treatment and better utilization of resources in health care. $(3,4,5)$ On the basis of this we ought to involve our patients at our Outpatient Clinic in Svendborg, but are we?

Objectives: To gain knowledge about how patients with rheumatoid arthritis experience involvement in treatment and care in the Rheumatology Outpatien Clinic, Svendborg.

Methods: An interview study of six patients with subsequent analysis based on Ricoeur. (6) Patient inclusion: patients with rheumatoid arthritis in remission by DAS28 for more than 2 years. The participants elected were 3 males and 3 female at the age of $30-78$ visiting the clinic during Marts and April 2019. They were asked about their experience of involvement from time of diagnosis until present time.

Results: The study provided knowledge that patient involvement was new to the participants. This is also found in other literature about patient involvement. $(7,8)$ All participants in this study felt involved in own care and treatment. The involvement was based on being seen and heard as persons with individual needs and not just as patients with arthritis. The way the participants experienced involvement showed that there are individual differences in how to provide the experience. In order to clarify what involvement meant for each patient, relationship with the health professional was necessary, as other studies also shows. $(7,8)$ The relationship was conditioned by continuity, trust, care and mutual respect. For all the participants informed consent was equal to involvement. Disease activity or fear of this was the main reason for feeling involved this way. Literature describes the same: amongst other factors, the severity of the disease is significant for the patients desire to be involved. $(7,8)$

Conclusion: The participants experienced involvement in own care and treatment. The relation to the health professional was important providing this experience. All defined involvement as informed consent as it also is to many healthcare professionals. (9) All participants needed time to reflect on what 